\title{
Smart Energy Meter
}

\author{
Ujawal Rajhans Akare ${ }^{1}$, Adit Dilip Keole ${ }^{2}$, Nikhil Santosh Bahakar ${ }^{3}$, Rohit Manohan Paunikar ${ }^{4}$ \\ ${ }^{1234}$ UG Students, Department of Electrical Engineering, Yashwantrao Chavan College of Engineering, Nagpur
}

Received on: 11 May, 2021, Revised on: 13 June, 2021, Published on: 15 June, 2021

\begin{abstract}
Power consumption monitoring is a very important task for the utility supply companies. Today most of the time door to door people visit for taking meter readings and so many times it is not possible for the reading taker if the housel industry is closed. Sometimes consumers who have not paid bills are not allowed to enter the person in home to take readings. To avoid such circumstances and to take the proper reading. In the proposed smart energy meter, the system gives the power consumed analysis using IoT on the cloud server. Also if any power theft occur then sms send to the power grid company.
\end{abstract}

Keywords- nodemcu, power, meter, IoT, SMS

\section{I- INTRODUCTION}

O ver the previous years, the electrical energy metering and billing system got updated and became easy to install with more features. IoT enables devices that can communicate via the internet and IP based network with each other in the form of data collection to monitor. IoT based Smart Energy consumption monitoring is an internet based device that measures the amount of power consumption. Nowadays, power consumption monitoring is a big issue in many areas.

The drawback of the current meter reading structure is such that a individual has to go home to read the meter reading. Several times faults like extra units or bill cost, or message from the grid companies despite the bills are paid-up. The concept is being suggested to lessen the individual effort and error to gather the monthly reading and to lessens the challenges with respect to the billing method. The proposed solution for this issue by installing the energy monitoring system for every individual house / industry to monitor the consumption of power online.

\section{II- LITERATURE REVIEW}

An attempt has been made by an author to design and implement a realistic paradigm of IoT operated smart electric meter reading device. The paradigm is used to measure the energy unit of the house or industry. It will also reduce the manual effort and will make the system smart and reliable. The model consists of an ESP 8266 wifi module interface with Arduino. The energy meter is connected to the arduino controller via an opto-coupler. A current sensor ACS712 is connected Ao input of an arduino which is analog. Theft can be detected using the current sensor if the power consumption is more as compared to the actual meter reading. [1]

The author in the paper introduce the execution of an unified smart energy metering technique using IoT. The proposed IoT meter reading system is designed to contribute to energy efficient smart cities implementation. Its main focus is to lessen the increase in mean electricity usage. It delivers the easy solution to problems faced from using the existing meter reading, such as manual reading inaccuracy from electromechanical meter. The standard and traditional old one metering system, where the end user is imposed bills on a monthly terms, bear inexplicable of the energy used for 


\section{International Journal of Innovations in Engineering and Science, www.ijies.net}

the rest of the month. The system is carried out in two sections, one on the end user side for IoT and other on the provider of services side for handling end user data from online. Android applications are also used to have an easily operated network at the end user side. The controlling unit includes generally of the Arduino microcontroller. The input is obtained from the sensing unit to arduino. The input data is processed then spent units in KWh by programming language. [2]

The improvement and influential framework for energy meters primarily has been addressed by the author. Aim is to monitor the energy consequently, the distant meter reading system is proposed. Distant energy meters were planned with a prepaid seizure structure. The data will be visible on the website on the cloud server. The structure design can monitor the condition and forward data to the web server and as well sends SMS via GSM as per the conditions set in programs like theft detection and meter reading. The authorized person can manage the large power system ON/OFF to make the system better via an online portal. The website is secured by adding username and password along with some API keys. The system will use ARM processors employed in the utilization of sensor modules and new conditions. Author also explains the controlling part of the system via loT [3]

The Author uses the concept of an energy meter employing IoT with Arduino. In this approach the author uses an Arduino controller as it is energy efficient and easy to program means it consumes less power. In this paper the energy meters which are mounted at home or industry side are not substituted, but the minor adjustment on such meters can modify the traditional meters into smart billing meters. GSM unit gives a notification via SMS. One can simply access the meter working via the online portal that was developed. Automatic ON \& OFF of meter is possible with the current meter reading. [4]

The existing meter reading paradigm is a laborious and difficult to conduct process and it require so much of manpower. The suggested structure is used for this problem and it is a worthwhile as well as a efficient process. The suggested structure gives the data of the power energy usage on the website using database, billing and paying via IoT portal, warning of power cutoff details, alarm systems when the energy usage surpass the limit and the disconnect of power via a message when the house-owner are out of home to avoid the loss of energy. In this system, a special id number is assigned for each meter system. This unique id number is linked with the consumer cell phone number. The energy usage from each home is sent to the command center online and the billing and power cutoff details are sent from the command center to the house owner energy meter cell phone number. [5]

\section{III- PROPOSED METHODOLOGY}

The system is installed in the individual House/ industry by replacing the old meter. The new system consists of NodeMCU wifi based controller, current sensor and voltage sensor. As $\mathrm{P}=\mathrm{VI}$ the power consumption will be calculated and the KWh will be calculated by the mathematical formula used in the programming. The Load is connected to the frid supply via this meter system. On LCD it shows the load power and total unit. The same data will be sent to the cloud server on a daily basis. The cloud server database is based on MySQL

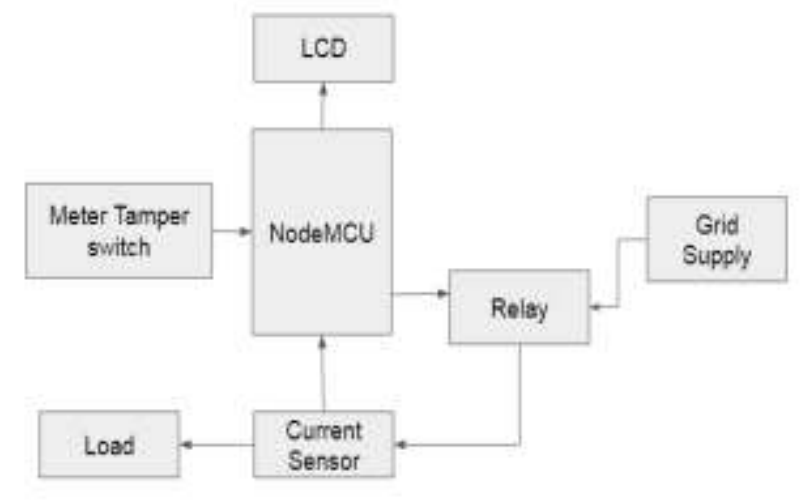

Fig. 1- System Block Diagram

\section{A. The System Hardware}

The main components of the system are NodeMCU as brain with wifi connectivity controller, Current sensor and GSM NodeMCU:- Wifi $2.4 \mathrm{GHz}$ ESP12 Microcontroller with 9 Digital IO pin and 1 analog pin. Easy to program with Arduino IDE. It is easily programmable as client or server architecture. In this project we are implementing the program of nodemcu as a server. When it is connected to the hotspot access point it gets the IP address of the network. This IP address when we put in the web browser we get the control panel buttons to control it.

The wireless range depends upon the range of wifi access point or hotspot to which the system is connected. 


\section{International Journal of Innovations in Engineering and Science, www.ijies.net}

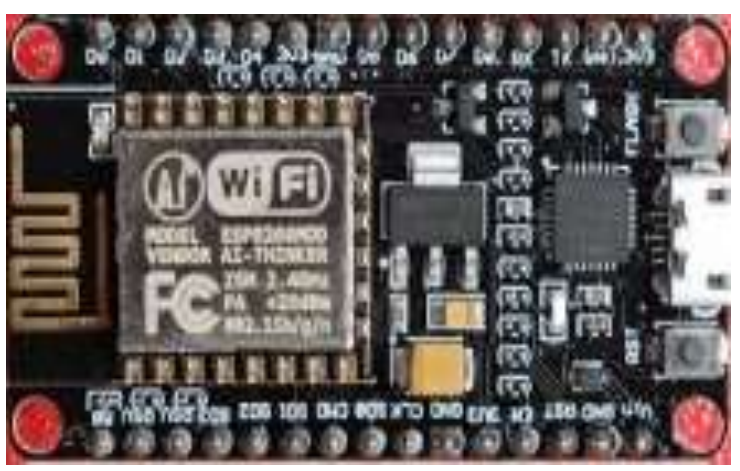

Fig. 2 -Node MCU 2.4GHz ESP 12

Current Sensor ACS172 is the hall effect based sensor that can accurately detect AC or DC current. It works on $5 \mathrm{~V} \mathrm{DC}$ and it can detect current range till 30Amps

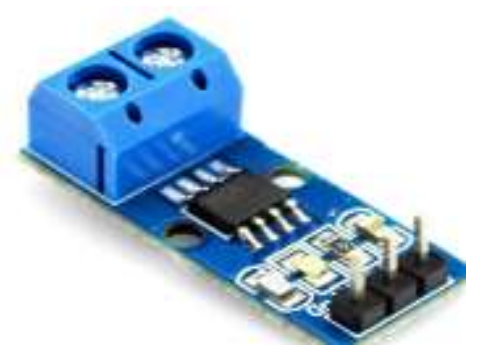

Fig 3-Current sensor

GSM module use to send sms to the consumer for the power consumption alert sms and higher authority for meter tampering

\section{B. Software and Programming}

Software use: Cloud server for data storage on MYSQL and online monitoring, Arduino IDE compiler for NodeMCU programming PHP script is served to accumulate the data to the database server. The NodeMCU is programmed to get the power consumption data of the system and send it to the cloud server database where the PHP script is used to get the data from the URL sent by the nodemcu. The LCD shows the data of unit consumption on the user side. If any meter tampering occur then SMS send to the authority as an intimation of power theft may possible

\section{IV- AdVANTAGES}

- Consumers can see the power usage online using the cloud server.

- It lessens the manpower to compile the monthly reading.

- If any meter tampering occurs then sms will send it to authority.

\section{V-CONCLUSION}

As per the study of the literature system will be designing and implementing the digital energy meter for home. Here the system will be implemented to work on a wifi network to transmit the power data to the cloud servers. The proposed system is based off on the IoT technology. So by using this system the manpower of taking meter reading door to door will be reduced.

\section{REFERENCES}

[1] Dr. Aditya Tiwary, "Design and Implementation of an Innovative Internet of Things (IOT) Based Smart Energy Meter" IJCSE ISSN: 2454-4248 Volume: 4 Issue: 4

[2] Maha Aboelmaged, Yasmeen Abdelghani "Wireless IoT based Metering System for Energy Efficient Smart Cities", 2017 29th International Conference on Microelectronics (ICM)

[3] A.Subba Rao, "IOT Based Smart Energy Meter Billing Monitoring and Controlling the Loads", International Journal of Innovative Technology and Exploring Engineering (IJITEE) ISSN: 2278-3075, Volume-8 Issue4S2 March, 2019

[4] Birendrakumar Sahani1, Tejashree Ravi, "IoT Based Smart Energy Meter", International Research Journal of Engineering and Technology (IRJET) e-ISSN: 2395 -0056 Volume: 04 Issue: 04 | Apr -2017

[5] Prathik.M, "Smart Energy Meter Surveillance Using IoT", IEEE International Conference on Power, Energy, Control and Transmission Systems (ICPECTS). 2018

[6] A. Tiwary, M. Mahato, M. Tripathi, M. Shrivastava, M. K. Chandrol, A. Chidar, "A Comprehensive Review of Smart Energy Meters: An Innovative Approach”, International Journal on Future Revolution in Computer Science \& Communication Engineering, Vol. 4, No. 4, April 2018.

[7] Himshekhar Das, L.C.Saikia, "GSM Enabled Smart Energy Meter and Automation of Home Appliances", PP978-1-4678-6503-1, 2015 IEEE.

[8] Pritee Mahajan and Prachi Jadhav, "Smart Meter: An IOT Based Meter for Live Electricity Monitoring and Bill Payment", IJEECS , 2017

[9] Vanishree and Sri G N Madhu, "GSM based Energy Meter Reading and Billing”, International Journal of Science and Research (IJSR), 2016.

[10] S.Visalatchi, "Smart energy metering and power theft control using arduino \& GSM", IEEE, 2017 